\title{
Suction duration and numbers of Araneae and Auchenorrhyncha collected in grassland when using an open-ended cylinder to define the sample area
}

\author{
Andrew Cherrill, Richard Burkmar, Henry Quenu \& Eman Zentane
}

\begin{abstract}
Cherrill, A., Burkmar, R., Quenu, H. \& Zentane, E. 2018: Suction duration and numbers of Araneae and Auchenorrhyncha collected in grassland when using an open-ended cylinder to define the sample area. — Entomol. Fennica 29: 105111.
\end{abstract}

Suction samplers are typically used with touch-down samples, where the nozzle is held stationary on the ground, or within an open-ended cylinder, where the nozzle is moved through the enclosed vegetation. With touch-down sampling, published estimates suggest that virtually all individuals and species of grassland invertebrate are captured within $3 \mathrm{~s}$. Effects of suction duration on catch when sampling within a cylinder have rarely been investigated. Here, it was found that extrapolation from studies of touch-down sampling, based on the relative areas of the G-vac nozzle and the cylinder, can be used to guide minimum sampling durations for Auchenorrhyncha (leafhoppers and planthoppers) when using a G-vac. Additional time, however, may be necessary when sampling Araneae (spiders), probably because movement of the G-vac nozzle within the cylinder results in disturbance of the vegetation such that more specimens are made available to be captured than with touch-down sampling.

A. Cherrill, Centre for Integrated Pest Management, Department of Crop and Environment Sciences, Harper Adams University, Shropshire, TF10 8NB, United Kingdom; E-mail: acherrill@harper-adams.ac.uk

R. Burkmar, Field Studies Council, Preston Montford, Shropshire, SY4 IHW, United Kingdom

H. Quenu, Department of Agriculture, Purpan School of Engineering, Toulouse Cedex 3, France

E. Zentane, Plant Protection Department, College of Agriculture, University of Tripoli, Libya.

Received 26 July 2017, accepted 23 November 2017

\section{Introduction}

Modified garden blow-vacs, commonly referred to as G-vacs, are used widely to sample grassland invertebrates and particularly Araneae (spiders) and Auchenorrhyncha (leafhoppers and planthoppers of the Hemipteran suborders Cicado- morpha and Fulgoromorpha) (Southwood \& Henderson 2000, Hill et al. 2005). G-vacs are popular because they are relatively inexpensive, and because they capture grassland invertebrates which live close to the ground. Such species are often under-represented in sweep-net samples (Samu \& Sarospataki 1995, Stewart \& Wright 
1995, Stewart 2002). G-vacs can also be used to obtain crude density estimates where sampling is conducted within an enclosed area - typically defined by an open-ended cylinder many times wider than the G-vac nozzle (Samu et al. 1997, Hill et al. 2005). The time required to capture all, or most invertebrates, when using a suction device within an open-ended sampling cylinder has, however, been investigated rarely (Henderson \& Whitaker 1977, Törmälä 1982).

In contrast, Brook et al. (2008) estimated that 90\% of Coleoptera, Araneae and Auchenorrhyncha species are captured in the first $3 \mathrm{~s}$ of suction when the nozzle of a Vortis device is held stationary on the ground at a single unenclosed point (commonly known as a "touch-down" sample). Moreover, Bell et al. (2000) found no increase in numbers of Araneae captured beyond the first $1 \mathrm{~s}$ suction of a touch-down sample when using a Gvac.

When using a cylinder, the time needed to capture a representative sample of invertebrates will be at least the minimum time required for a single touch-down sample multiplied by the ratio of the area of the cylinder to that of the nozzle. Longer may be required, however, because movement of the nozzle within the cylinder may enhance capture of specimens that would otherwise be hidden beneath the vegetation. The present study addresses this problem by investigating the numbers of individuals and species of Araneae and Auchenorrhyncha captured with increasing sample duration when using a G-vac within an open-ended cylinder at each of three grasslands. In this study, the G-vac nozzle had an area of $0.01 \mathrm{~m}^{2}$, while the area of the cylinder was $0.18 \mathrm{~m}^{2}$.

If it is assumed that a period of $3 \mathrm{~s}$ is appropriate for a touch-down sample, then most specimens would be expected to have been captured from the cylinder in just under $60 \mathrm{~s}$ (i.e. 18 multiplied by $3 \mathrm{~s}$ to give an equivalent sampling intensity in terms of seconds per $\mathrm{m}^{2}$ ). To test this hypothesis three successive samples of $30 \mathrm{~s}$ were taken from within the cylinder such that the accumulation of specimens and species could be investigated after $30 \mathrm{~s}, 60 \mathrm{~s}$ and $90 \mathrm{~s}$ sampling.

\section{Methods}

\subsection{Study sites}

Three grassland sites with flat terrain and internally homogenous vegetation were selected to include a range of agricultural management regimes. Site 1 was an ungrazed grassland, mown at intervals from mid-July onwards (altitude $60 \mathrm{~m}$, latitude $52^{\circ} 46^{\prime} \mathrm{N}$, longitude $2^{\circ} 25^{\prime} \mathrm{W}$ ). Site 2 was an unmown pasture grazed by dairy cattle and situated within $500 \mathrm{~m}$ of Site 1 . Site 3 was unimproved sheep-grazed grassy heath (altitude 420 $\mathrm{m}$, latitude $52^{\circ} 31^{\prime} \mathrm{N}$, longitude $2^{\circ} 53^{\prime} \mathrm{W}$ ). Vegetation at Sites 1 and 2 was dominated by sown grasses and was representative of mesotrophic grassland type MG7a Lolium perenne - Trifolium repens ley within the National Vegetation Classification (NVC) (Rodwell 1992). Site 3 was dominated by semi-natural vegetation characteristic of poor acidic soils and was most similar to NVC type U1 Festuca ovina - Agrostis capillaris Rumex acetosella.

At each site, a grid $12 \mathrm{~m}$ by $20 \mathrm{~m}$ was marked out and sub-divided into fifteen $4 \mathrm{~m}$ by $4 \mathrm{~m}$ gridsquares. Vegetation height was quantified using a single drop-plate measurement (Cherrill \& Rushton 1993) at the centre of each grid-square $(\bar{x} \pm$ $S D$ : Site 1, $12.3 \pm 2.2 \mathrm{~cm}$; Site 2, $15.1 \pm 3.4 \mathrm{~cm}$; Site $3,3.7 \pm 1.0 \mathrm{~cm})(n=15$ at each site $)$.

\subsection{Suction sampling}

The G-vac suction sampler was a modified McCulloch GBV 345 garden blower/vacuum (Stewart \& Wright 1995, Stewart 2002). The end of the collecting pipe was sawn off perpendicular to its length to give a nozzle with a cross sectional area of $0.01 \mathrm{~m}^{2}$. A nylon $1 \mathrm{~mm}$ mesh bag was held in place at the end of the pipe by a rubber band. Estimated air velocity within the nozzle was 20.3 $\mathrm{ms}^{-1}$ (Zentane et al. 2016).

Suction samples at each site were taken on a single day only $\left(15^{\text {th }}, 17^{\text {th }}\right.$ and $21^{\text {st }}$ July 2014 for Sites 1, 2 and 3 respectively). Minimum air temperatures during sampling, measured in shade at 1 $\mathrm{m}$ above ground using a dry bulb mercury thermometer, at the three sites were $30^{\circ} \mathrm{C}, 26^{\circ} \mathrm{C}$ and $24{ }^{\circ} \mathrm{C}$ respectively. Vegetation and leaf litter was dry to the touch. 
Table 1. Total numbers of individuals and species of Araneae collected after $90 \mathrm{~s}$ suction sampling.

\begin{tabular}{|c|c|c|c|}
\hline & Site 1 & Site 2 & Site 3 \\
\hline \multicolumn{4}{|l|}{ Theridiidae } \\
\hline Enoplognatha latimana Hippa \& Oksala, 1982 & 4 & 0 & 0 \\
\hline \multicolumn{4}{|l|}{ Linyphiidae } \\
\hline Dicymbium nigrum (Blackwall, 1834) & 1 & 1 & 0 \\
\hline Entelecara flavipes (Blackwall, 1834) & 0 & 0 & 1 \\
\hline Dismodicus bifrons (Blackwall, 1841) & 0 & 0 & 0 \\
\hline Oedothorax fuscus (Blackwall, 1834) & 7 & 6 & 4 \\
\hline Oedothorax retusus (Westring, 1851) & 12 & 2 & 0 \\
\hline Gongylidiellum vivum (O.P.-Cambridge, 1875) & 2 & 0 & 0 \\
\hline Micrargus herbigradus (Blackwall, 1854) & 0 & 0 & 1 \\
\hline Micrargus subaequalis (Westring, 1851) & 1 & 0 & 0 \\
\hline Savignia frontata Blackwall, 1833 & 5 & 6 & 1 \\
\hline Milleriana inerrans (O.P.-Cambridge, 1885) & 1 & 0 & 0 \\
\hline Erigone dentipalpis (Wider, 1834) & 2 & 17 & 3 \\
\hline Erigone atra Blackwall, 1833 & 9 & 44 & 3 \\
\hline Agyneta decora (O.P.-Cambridge, 1871) & 2 & 0 & 0 \\
\hline Meioneta rurestris (C.L. Koch, 1836) & 0 & 2 & 0 \\
\hline Bathyphantes gracilis (Blackwall, 1841) & 18 & 53 & 0 \\
\hline Tenuiphantes tenuis (Blackwall, 1852) & 13 & 42 & 0 \\
\hline Microlinyphia pusilla (Sundevall, 1830) & 3 & 0 & 0 \\
\hline \multicolumn{4}{|l|}{ Thomisidae } \\
\hline Xysticus cristatus (Clerck, 1757) & 1 & 0 & 0 \\
\hline \multicolumn{4}{|l|}{ Immatures } \\
\hline Unidentified families & 162 & 182 & 7 \\
\hline Linyphiidae & 100 & 193 & 7 \\
\hline Tetragnathidae & 6 & 0 & 0 \\
\hline Lycosidae & 29 & 0 & 0 \\
\hline Thomisidae & 1 & 0 & 1 \\
\hline Total number of individuals & 379 & 548 & 28 \\
\hline Number of species & 15 & 9 & 6 \\
\hline
\end{tabular}

G-vac samples were taken within an openended plastic cylinder with a cross-sectional area of $0.18 \mathrm{~m}^{2}$, height of $60 \mathrm{~cm}$ in height and weight of $5 \mathrm{~kg}$ (sufficient to form a seal with the ground surface). The cylinder was placed at the centre of a grid-square. The G-vac was then used to take three successive $30 \mathrm{~s}$ sub-samples before the cylinder was moved to the next grid-square. The motor was run on full-throttle whilst the nozzle was within the cylinder, but was idled whilst the mesh bag was replaced between $30 \mathrm{~s}$ sub-samples. Within each $30 \mathrm{~s}$ sub-sample, the G-vac nozzle was swept over the surface of the vegetation for 5 $\mathrm{s}$ before the nozzle was repeatedly lowered and raised from the ground surface in a series of overlapping "touch-downs" covering the enclosed area for the remaining $25 \mathrm{~s}$. Changing the mesh bag between sub-samples took approximately 15 s and, although not quantified, it is possible that a small number of active fliers may have escaped from the cylinder while this was being done.

\subsection{Treatment of invertebrate samples}

Material from the three $30 \mathrm{~s}$ sub-samples in each grid-square were counted separately. Adult Araneae and Auchenorrhyncha were identified to species, while immature specimens were identified to family. Nomenclature follows Merrett et al. (2014) and Wilson et al. (2015).

\subsection{Statistical analysis}

Repeated measures Generalised Linear Model with negative binomial error distribution was used within IBM SPSS ver 24 to test for an effect 
Table 2. Total numbers of individuals and species of Auchenorrhyncha collected after 90 s suction sampling.

\begin{tabular}{lccc}
\hline & Site 1 & Site 2 & Site 3 \\
\hline Cicadellidae & & & \\
$\quad$ Aphrodes bicinctus (Schrank, 1776) & 3 & 0 & 0 \\
$\quad$ Anoscopus albifrons (Linnaeus, 1758) & 2 & 0 & 0 \\
$\quad$ Anoscopus serratulae (Fabricius, 1775) & 3 & 0 & 0 \\
Anoscopus unidentified females & 2 & 0 & 0 \\
Deltocephalus pulicaris (Fallen, 1806) & 0 & 0 & 19 \\
Arocephalus punctum (Flor, 1861) & 0 & 0 & 2 \\
Arthaldeus pascuellus (Fallen, 1826) & 60 & 2 & 0 \\
Psammotettix nodosus (Ribaut, 1925) & 0 & 0 & 2 \\
Euscelis incisus (Kirshbaum, 1858) & 37 & 0 & 0 \\
Cicadula persimilis (Edwards, 1920) & 1 & 0 & 0 \\
Zyginidia scutellaris (Herrich-Schaeffer, 1838) & 22 & 0 & 0 \\
Delphacidae & & & 0 \\
$\quad$ Javesella obscurella (Boheman, 1847) & 0 & 4 & 0 \\
Javesella pellucida (Boheman, 1847) & 202 & 30 & 3 \\
Javesella unidentified females & 0 & 23 & 0 \\
Immatures & & & 26 \\
$\quad$ Cicadellidae & 116 & 3 & 3 \\
Delphacidae & 292 & 23 & \\
Total number of individuals & 740 & 85 & 3 \\
Number of species & 8 & & \\
\hline
\end{tabular}

of the independent variable "sample duration" (30,60 and $90 \mathrm{~s})$ on the dependent variable which was the accumulated number of individuals (or species). The analysis was conducted for Araneae and Auchenorrhyncha within each site separately. In each analysis, the between-subject factor was grid-square and the within-subject factor was sample duration. Detection of a significant effect of sample duration, based on Walds Chisquare Test (with critical $P$ of 0.05 ), was followed by Bonferroni-corrected pairwise comparisons between accumulated numbers captured after 30 , 60 and $90 \mathrm{~s}$.

At Sites 1 and 2, all means (and Standard Errors, $S E$ ) are based on data from 15 grid-squares, while at Site 3 some samples were mislaid leaving data for 10 grid-squares only.

\section{Results}

In total 955 specimens of Araneae and 851 Auchenorrhyncha were captured across the three sites. Nineteen species of Araneae and twelve species of Auchenorrhyncha were found (Tables 1 and 2).

\subsection{Numbers of individuals}

Sample duration had a significant effect on the cumulative number of Araneae captured at Site 1 $\left(\chi^{2}=14.56\right.$, d.f. $\left.=2, P=0.01\right)$ and Site $2\left(\chi^{2}=\right.$ 70.54, d.f. $=2, P=<0.001)$, but not Site $3\left(\chi^{2}=\right.$ 3.21 , d.f. $=2, P=0.20)$. At both Sites 1 and 2, numbers increased with each additional $30 \mathrm{~s}$ subsample. In contrast, at Site 3 very few additional Araneae were captured in the second and third 30 s sub-samples (Fig. 1a).

Sample duration had a significant effect on the cumulative number of Auchenorrhyncha at

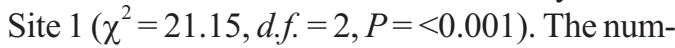
ber of individual Auchenorrhyncha increased in the second $30 \mathrm{~s}$ sub-sample only, with few added in the third $30 \mathrm{~s}$ (Fig. 1c). Sample duration had no significant effect on cumulative numbers captured at Site $2\left(\chi^{2}=2.07, d . f .=1, P=0.15\right)$ or Site $3\left(\chi^{2}=2.05\right.$, d.f. $\left.=1, P=0.11\right)$. At these sites, very few additional specimens were captured in the second $30 \mathrm{~s}$ sub-sample, and none were captured in the third $30 \mathrm{~s}$ (with the consequence that the third sub-sample was omitted from these analyses) (Fig. 1c). 
a) Araneae - abundance

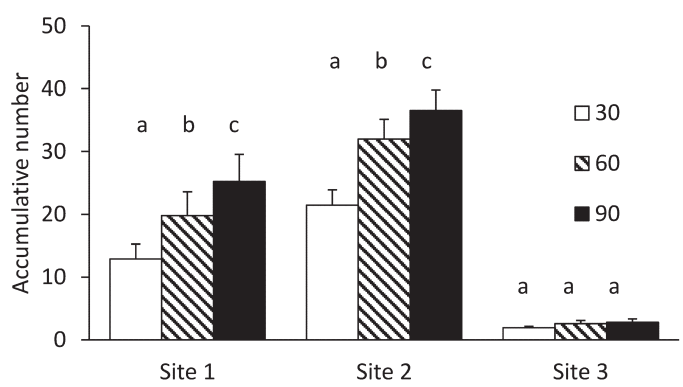

c) Auchenorrhyncha - abundance

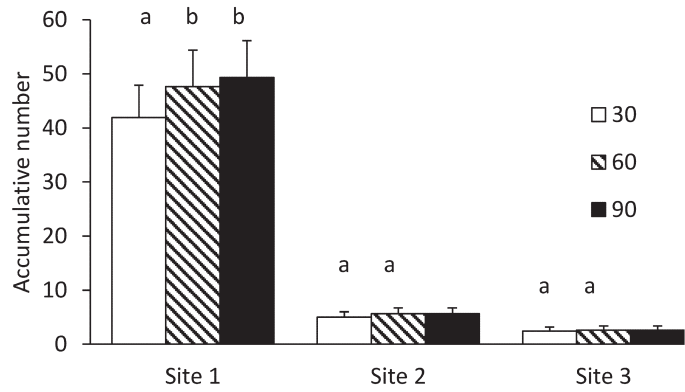

b) Araneae - species richness

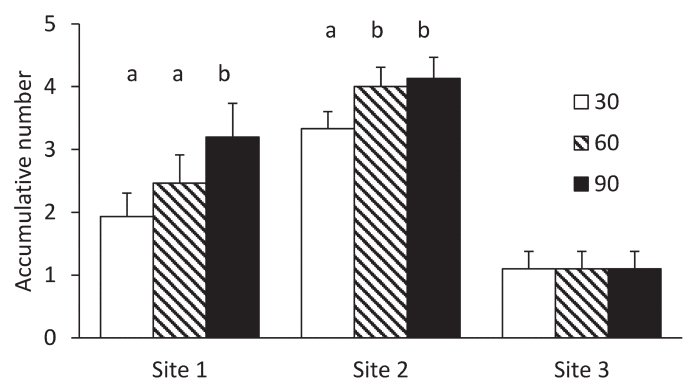

d) Auchenorrhyncha - species richness

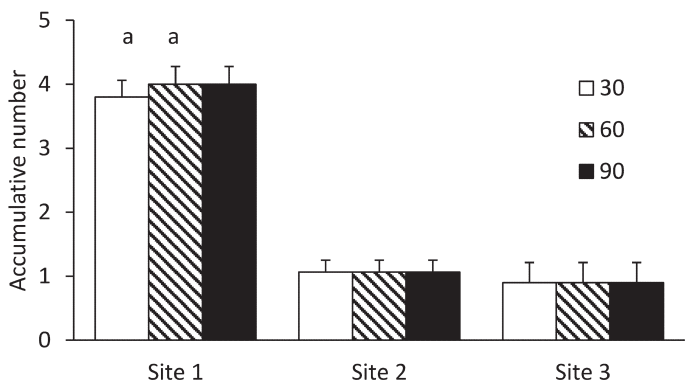

Fig. 1. Mean $( \pm S E)$ for accumulative numbers of individuals and species of Araneae and Auchenorrhyncha captured after $30 \mathrm{~s}, 60 \mathrm{~s}$ and $90 \mathrm{~s}$. Columns within a site, and bearing the same letter, were subject to statistical analysis and were found to be not significantly different (at $P=0.05$ ). Columns without a letter have identical mean and SE to the adjacent column(s). Means are based on $n=15$ at Sites 1 and 2, and $n=10$ at Site 3.

\subsection{Numbers of species}

Sample duration had a significant effect on the cumulative number of species of Araneae captured at Site $1\left(\chi^{2}=11.82, d . f .=2, P=<0.01\right)$ and Site $2\left(\chi^{2}=27.48, d . f .=2, P=<0.001\right)$. The mean number of Araneae species increased in the third $30 \mathrm{~s}$ sub-sample at Site 1, and in the second $30 \mathrm{~s}$ sub-sample at Site 2 (Fig. 1b). At Site 3, no additional species were found in the second or third 30 s sub-samples and hence these data were not subject to statistical analysis (Fig. 1b).

At Site 1, the number of Auchenorrhyncha species showed a small non-significant increase in the second $30 \mathrm{~s}$ sub-sample $\left(\chi^{2}=3.16, d . f .=1\right.$, $P=0.08)$, but no additional species were captured in the final $30 \mathrm{~s}$ (Fig. 1d). Moreover, no additional species were captured after the first $30 \mathrm{~s}$ subsample at either Site 2 or 3 and hence these data were not subject to statistical analysis (Fig. 1d).

\section{Discussion}

Several studies have investigated how numbers of species and specimens increase with suction time using touch-down samples (Macleod et al. 1994, Bell et al. 2000, Brook et al. 2008). Macleod et al. (1994) used a G-vac to repeatedly sample the same unenclosed point with consecutive touch-downs up to a total duration of $160 \mathrm{~s}$. Cumulative numbers of Coleoptera and Araneae increased from the first $5 \mathrm{~s}$ sub-sample to $30 \mathrm{~s}$ but not thereafter. The time after which no further benefit accrued may have been overestimated because specimens were probably drawn in from surrounding vegetation as the G-vac was repeatedly raised and lowered (Samu et al. 1997, Cherrill 2015). This problem was overcome by Bell et al. (2000) and Brook et al. (2008) who sampled independent points for different durations. These authors suggest that most Araneae and Auchenorrhyncha are captured within the first few seconds of a touch-down sample. Bell et al. (2000) found no increase in numbers or species of spiders between $1 \mathrm{~s}$ and $10 \mathrm{~s}$ suction with a 
G-vac. Brook et al. (2008) estimated that $90 \%$ of individuals and species of Coleoptera, Araneae and Auchenorrhyncha are captured within 3 s using a similar Vortis suction device. In a direct comparison of the two devices, Zentane et al. (2016) found the Vortis to be less efficient than a G-vac, hence these estimates can be viewed as being broadly comparable.

In the present study, the G-vac nozzle was used to sweep the upper layers of the vegetation before being applied in a series of overlapping touch-downs within a cylinder of area $0.18 \mathrm{~m}^{2}$. A $30 \mathrm{~s}$ sub-sample therefore approximates to a sampling intensity of approximately $1.7 \mathrm{~s}$ per $0.01 \mathrm{~m}^{2}$ (i.e. $30 \mathrm{~s}$ divided by 18). Based on Bell et al. (2000) and Brook et al. (2008), touch-down sampling within the cylinder for 60 s (i.e. equivalent to approximately $3.4 \mathrm{~s}$ per $0.01 \mathrm{~m}^{2}$ touchdown) would be predicted to have captured nearly all specimens and species therein. Although the approach to sampling within these studies was not identical, the prediction agrees with the results reported here for Auchenorrhyncha. Numbers of individuals and species did not increase after $60 \mathrm{~s}$ at any of the three sites (Figs. 1c and 1d).

In contrast, numbers of individuals and species of Araneae accumulated beyond $60 \mathrm{~s}$ sampling, except at Site 3 where Araneae were relatively scarce (Figs. 1a and 1b). Overall, the results suggest that sampling within the cylinder for $60 \mathrm{~s}$ (crudely equivalent to a series of twenty $3 \mathrm{~s}$ touch-downs) was sufficient for Auchenorrhyncha. Longer may be needed, however, to reach the point where further sampling captures no additional Araneae. The efficiency of sampling may be related to the structural complexity of the vegetation, because at the site with the shortest grass (Site 3) no additional Araneae were caught after the first $30 \mathrm{~s}$ (Figs. 1a and 1b). Suction sampling is generally more efficient in short vegetation (Henderson \& Whitaker 1997, Hossain et al. 1999, Brook et al. 2008, but see Sanders \& Entling 2011) and it is also known that less structurally complex grasslands tend to support fewer invertebrates (Langellotto et al. 2004, Horvath et al. 2009).

The present study provides partial support for the hypothesis that when using a G-vac within an open-ended cylinder, the minimum necessary suction duration can be extrapolated from studies using the alternative touch-down approach. A sampling intensity equivalent to $3 \mathrm{~s}$ per unit area (where unit area is defined by the cross-sectional area of the nozzle) is sufficient to capture all species and nearly all individuals of Auchenorrhyncha, but longer may be needed for Araneae, and particularly in taller grass. This is probably because movement of the nozzle within a cylinder results in disturbance of the vegetation such that more Araneae are made available to be captured than with touch-down sampling.

Acknowledgements. We thank Chris Hickman for assistance with field work, Nigel Cane-Honeysett for assistance with spider identification, Simon Jeffery for assistance with producing the figure, and two anonymous referees whose comments greatly improved the manuscript. Dr E. Zentane was supported by a sabbatical from the University of Tripoli. Henry Quenu was supported by the internship programme at Purpan School of Engineering, France.

\section{References}

Bell, J., Wheater, C. P., Henderson, R. \& Cullen, R. 2000: Testing the efficiency of suction samplers (G-vacs) on spiders: the effect of increasing nozzle size and suction time. - In: Toft, S. \& Scharff, N. (eds.), European Arachnology: 285-290. Aarhus University Press, Denmark. $358 \mathrm{pp}$.

Brook, A. J., Woodcock, B. A., Sinka, M. \& Vanbergen, A. J. 2008: Experimental verification of suction sampler capture efficiency in grasslands of differing vegetation height and structure. - Journal of Applied Ecology 45: $1357-1363$.

Cherrill, A. J. 2015: Suction sampling of grassland invertebrates using the G-vac: Quantifying and avoiding peripheral suction effects. - European Journal of Entomology 112: 520-524.

Cherrill, A. J. \& Rushton, S. P. 1993: The Auchenorrhyncha of an unimproved moorland in northern England. - Ecological Entomology 18: 95-103.

Henderson, I. \& Whitaker, T. 1977: The efficiency of an insect sampler in grassland. - Ecological Entomology 2: $57-60$.

Hill, D., Fasham, M., Tucker, G., Shrewry, M. \& Shaw, P. 2005: Handbook of biodiversity methods. - Cambridge University Press, Cambridge. 588 pp.

Horvath, R., Magura, T., Szinetar, C. \& Tothmeresz, B. 2009: Spiders are not less diverse in small and isolated grasslands, but less diverse in overgrazed grasslands: A field study (East Hungary, Nyirseg). - Agriculture, Ecosystems and Environment 130: 16-22.

Hossain, Z., Gurr, G. M. \& Wratten, S. D. 1999: Capture efficiency of insect natural enemies from tall and short 
vegetation using vacuum sampling. - Annals of Applied Biology 135: 463-467.

Langellotto, G. A. \& Denno, R. F. 2004: Responses of invertebrate natural enemies to complex-structured habitats: a meta-analytical synthesis. - Oecologia 139: $1-10$.

Macleod, A., Wratten, S. D. \& Harwood, R. W. J. 1994: The efficiency of a new lightweight suction sampler for sampling aphids and their predators in arable land. - Annals of Applied Biology 124: 11-17.

Merrett, P., Russell-Smith, A. \& Harvey, P. 2014: A revised checklist of British spiders. - Arachnology 16: 134 144.

Rodwell, J. S. 1992: British Plant Communities. Volume 3. Grasslands and montane communities. - Cambridge University Press, Cambridge. 552 pp.

Samu, F., Nemeth, J. \& Kiss, B. 1997: Assessment of the efficiency of a hand-held suction device for sampling spiders: improved density estimation or oversampling? - Annals of Applied Biology 130: 371-378.

Samu, F. \& Sarospataki, M. 1995: Design and use of a hand-held suction sampler, and its comparison with sweep net and pitfall trap sampling. - Folia Entomologia Hungarica 56: 195-203.
Sanders, D. \& Entling, M. H. 2011: Large variation of suction sampling efficiency depending on arthropod groups, species traits and habitat properties. - Entomologia Experimentalis et Applicata 138: 234-243.

Southwood, T. R. E. \& Henderson, P. A. 2000: Ecological methods. $3^{\text {rd }}$ Ed. - Blackwell Science, Oxford. 575 pp.

Stewart A. J. A. \& Wright A. F. 1995: A new inexpensive suction apparatus for sampling arthropods in grasslands. - Ecological Entomology 20: 98-102.

Stewart, A. J. A. 2002: Techniques for sampling Auchenorrhyncha in grasslands. - Denisia 4: 491-512.

Törmaälä, T. 1982: Evaluation of five methods of sampling field layer arthropods, particularly the leafhopper community, in grassland. - Annales Entomologici Fennici 48: 1-16.

Wilson, M., Stewart, A., Biedermann, R., Nickel, H. \& Niedringhaus, R. 2015: The planthoppers and leafhoppers of Britain and Ireland. - Cicadina - Supplement 2: 1-138.

Zentane, E., Quenu, H., Graham, R. I. \& Cherrill, A. 2016: Suction samplers for grassland invertebrates: comparison of numbers caught using Vortis and G-vac devices. - Insect Conservation and Diversity 9: 470-474. 